\title{
Correction to: Insights on Droplet Digital PCR-Based Cellular Kinetics and Biodistribution Assay Support for CAR-T Cell Therapy
}

\author{
Hiroshi Sugimoto, ${ }^{1,4}$ (D) Susan Chen, ${ }^{2}$ Jean-Pierre Minembe, ${ }^{2}$ Johara Chouitar, ${ }^{3}$ Xingyue He, ${ }^{3}$ Haiqing Wang, ${ }^{2}$ \\ Xiaodong Fang, ${ }^{2,4}$ and Mark G. Qian ${ }^{2}$
}

published online 31 March 2021

\section{Correction to: The AAPS Journal volume 23, Article number: 36 (2021) \\ https://doi.org/10.1208/s12248-021-00560-6}

A formatting error occurred on the following equation during the production process.

Incorrect:

Concentration $=-\ln \left(\frac{\frac{\text { Number of negative droplets }}{\text { Number of total droplets }}}{\mathrm{V}_{\text {droplet }}}\right)$

Correct

Concentration $=-\frac{\ln \left(\frac{\text { Number of negative droplets }}{\text { Number of total droplets }}\right)}{\mathrm{V}_{\text {droplet }}}$

The original article has been corrected.

Publisher's Note Springer Nature remains neutral with regard to jurisdictional claims in published maps and institutional affiliations.

The online version of the original article can be found at https:// doi.org/10.1208/s12248-021-00560-6

\footnotetext{
${ }^{1}$ Department of Drug Metabolism and Pharmacokinetics, Takeda Pharmaceuticals International Co, 125 Binney Street, Cambridge, MA 02142, USA.

${ }^{2}$ Department of Drug Metabolism and Pharmacokinetics, Takeda Pharmaceuticals International Co, 35 Landsdowne Street, Cambridge, MA 02139, USA.

${ }^{3}$ Department of Immuno Oncology DDU, Takeda Pharmaceuticals International Co, 40 Landsdowne Street, Cambridge, MA 02139, USA.

${ }^{4}$ To whom correspondence should be addressed. (e-mail: Hiroshi.Sugimoto@takeda.com; Xiaodong.Fang@takeda.com)
} 